\title{
Hydrogeological and geophysical study for deeper groundwater resource in quartzitic hard rock ridge region from $2 \mathrm{D}$ resistivity data
}

\author{
Dewashish Kumar*, V Ananda Rao and V S Sarma \\ CSIR-National Geophysical Research Institute, Hyderabad 500 00\%, India. \\ *Corresponding author.e-mail: dewashishkumar@ngri.res.in
}

\begin{abstract}
Electrical resistivity method is a versatile and economical technique for groundwater prospecting in different geological settings due to wide spectrum of resistivity compared to other geophysical parameters. Exploration and exploitation of groundwater, a vital and precious resource, is a challenging task in hard rock, which exhibits inherent heterogeneity. In the present study, two-dimensional Electrical Resistivity Tomography (2D-ERT) technique using two different arrays, viz., pole-dipole and pole-pole, were deployed to look into high signal strength data in a tectonically disturbed hard rock ridge region for groundwater. Four selected sites were investigated. 2D subsurface resistivity tomography data were collected using Syscal Pro Switch-10 channel system and covered a $2 \mathrm{~km}$ long profile in a tough terrain. The hydrogeological interpretation based on resistivity models reveal the water horizons trap within the clayey sand and weathered/fractured quartzite formations. Aquifer resistivity lies between $\sim 3-35$ and 100-200 $\Omega \mathrm{m}$. The results of the resistivity models decipher potential aquifer lying between 40 and $88 \mathrm{~m}$ depth, nevertheless, it corroborates with the static water level measurements in the area of study. The advantage of using pole-pole in conjunction with the pole-dipole array is well appreciated and proved worth which gives clear insight of the aquifer extent, variability and their dimension from shallow to deeper strata from the hydrogeological perspective in the present geological context.
\end{abstract}

\section{Introduction}

An acute shortage of water supply and declining trend of groundwater from the existing tubewells had been noticed in the Jamia Hamdard University campus, New Delhi. To meet the ever increasing demand of water, it had been planned to develop a rainwater harvesting structure to recharge the subsurface in order to augment the water table situation in the quartzite hard rock aquifer system. At the same time resistivity investigations both conventional $1 \mathrm{D}$ and multielectrode $2 \mathrm{D}$ imaging had been done to locate the prospect and potential groundwater zones for exploration for long term sustainability. It is well known that the direct current (DC) electrical resistivity technique is being widely used to image the geoelectric structure of the shallow subsurface earth (Keller and Frischknecht 1966; Bhattacharya and Patra 1968; Zohdy et al. 1974; Parasnis 1986; Giao et al. 2003; Kumar et al. 2007). The major limitation of the conventional vertical electrical sounding (VES) is the assumption of a 1D earth model that does not really occur in most of the practical subsurface geological situations and especially in hard rock regions. Electrical Profiling (EP) technique

Keywords. Electrical resistivity tomography; hard rock region; weathered/fractured quartzite formation; groundwater. 
too gives only one depth level information (Giao et al. 2003) of the subsurface formation. Secondly, conventional resistivity methods acquire limited number of data points and it takes longer time for data acquisition. The resistivity model derived from inversion of $1 \mathrm{D}$ data results in poor resolution especially for deeper boundaries and gives only point vertical information (Bhattacharya and Patra 1968). On the other hand, two-dimensional electrical resistivity tomography (2D-ERT) technique had advantages over conventional resistivity and had been studied by many authors (Griffiths and Barker 1993; Daily et al. 2004; Adepelumi et al. 2006; Kumar et al. 2010; Robert et al. 2011). One of the principal advantages of multielectrode resistivity measurements/tomography is that the technique affords distinct view of the geoelectrical changes within the regolith which is readily related to the changes in the porosity and permeability values anticipated in a typical vertical profile through the regolith in crystalline rocks (Owen et al. 2005). The interpreted 2D inverted resistivity model of the subsurface represents hydrogeological conditions, structural features, resistive and conductive formations which had been studied by many researchers, viz., Krishnamurthy et al. (2000), Batayneh Awni (2001), Kumar (2004), Kumar et al. (2008, 2010, 2011), Rao et al. (2008), Ratnakumari et al. (2012). Kumar et al. (2011) had studied about the sensitivity analysis of $2 \mathrm{D}$ resistivity datasets covering different geomorphic units in basaltic hard rock for groundwater problem. In another study, Owen et al. (2005) find that this technique produced high resolution images of the subsurface which are useful for groundwater resources assessment and is successful in identifying potential zones for groundwater such as areas with a maximum depth of weathered regolith, zones of fracturing and faulting and high porosity and permeability zones associated with lithological contacts. The method appropriately well suited for characterization of crystalline basement rocks and their weathered regolith profiles (Owen et al. 2005; Kumar et al. 2010, 2011). Revil et al. (2012) in their recent research had explained about the low-frequency electrical methods for subsurface characterization and monitoring in hydrogeology. Abdulaziz et al. (2012) in their work demonstrated subsurface characterization and groundwater flow. Though multi electrode resistivity tomography technique is more expensive compared to traditional DC resistivity survey, the additional cost may be justified where the prospecting, exploration and demand for groundwater is relatively high especially in heterogeneous, rugged and different geological settings.

\section{Geological setting of the study area}

The present work is carried out in the Jamia Hamdard University located at about $7 \mathrm{~km}$ east of historical monumemt Qutub Minar and between Tara Apartments and Batra Hospital by the side of Mehraulu-Badarpur road, New Delhi. The Hamdard University is located on the flank of the ridge which forms the northeastern extension of the Aravali hill range (figure 1a). The relief of the area is $230 \mathrm{~m}$ amsl. Locally the ridge has a northeastsouthwest trend. The drainage pattern is dendritic to parallel in nature (IGGS Report 2001; Rao et al. 2006). The stratigraphy succession of the geological formations of the studied area is presented as detailed geological map and is shown in figure 1(b).

The study area is underlain by quartzitic scree and slopping towards north and northeast directions. It falls on the Delhi ridge comprising of quartzites, schists and phyllites which are complex type of hard rocks. A network of joints, fault planes, bedding planes, weathered, fractured and saturated fractured zones which act as a secondary porosity forms the aquifer system. In general, quartzites are thought to be resistant however, the presence of small amounts of pyrite in the quartzites make them vulnerable to weathering. It is observed that weathering of proterozoic quartzite in the semi-arid conditions around Delhi proceeded from fractures towards the inside and produced weathering rinds. This makes the quartzite formation in Delhi porous and subsequently friable rock. The total disintegration of grain to grain contacts imparted friability to this quartzite to produce silica sand. Subsequent physical erosion of loose sand produced during rind development in the outermost zones give rise to features like tors, spheroids, gullies and cavities. These cavities vary from centimetric to metric scale on the quartzites. Interestingly, the terrain acquired ruggedness even in semi-arid conditions. The structural features are mainly responsible to maintain the hydraulic continuity within the aquifer system. A typical semi-arid climate is prevalent in the area. The southwest monsoon occurred between June and September months of the year and the rainfall is the main source of recharge to the aquifer. Joints and fracture system of the in situ rock acts as the major conduit of recharge to the groundwater. The water levels varied from 12 to $15 \mathrm{~m}$ below ground level (bgl) suggesting healthy condition of the aquifer during the year 2001, while in the year 2005 , the water level had gone down due to excess pumping and overexploitation of groundwater. The depth of static water levels measured in different borewells in the campus and surrounding the study area varies from 49.05 to $65.60 \mathrm{~m}$ bgl which says 


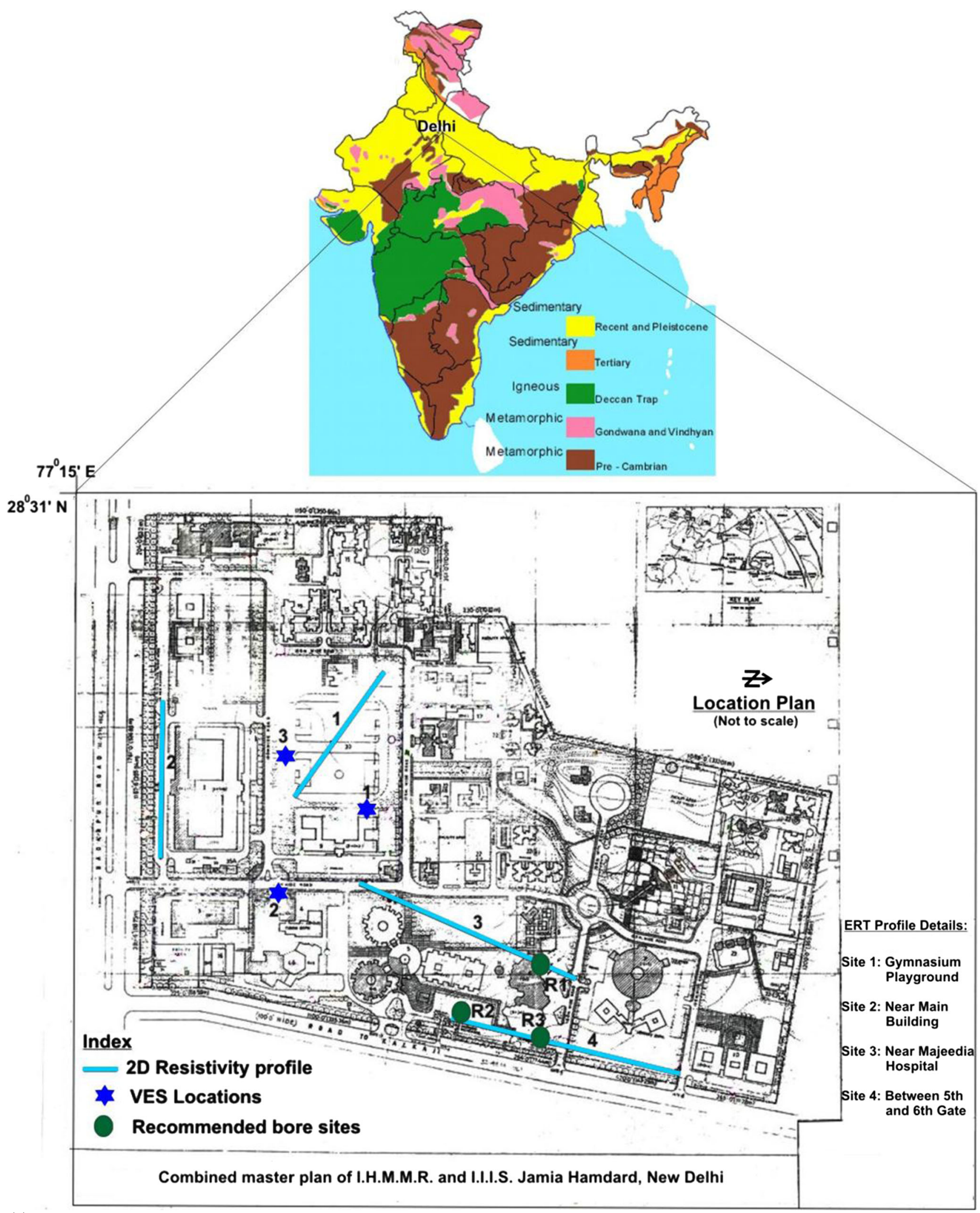

(a)

Figure 1. (a) Location map of the study area showing 2D-ERT, VES and recommended borewell sites (www.mapsofindia. commaps/India/geological). (b) Detailed geological map showing major lithotectonic units of the study area (after Kaur et al. 2009). NDFB - North Delhi Fold Belt and SDFB - South Delhi Fold Belt. 


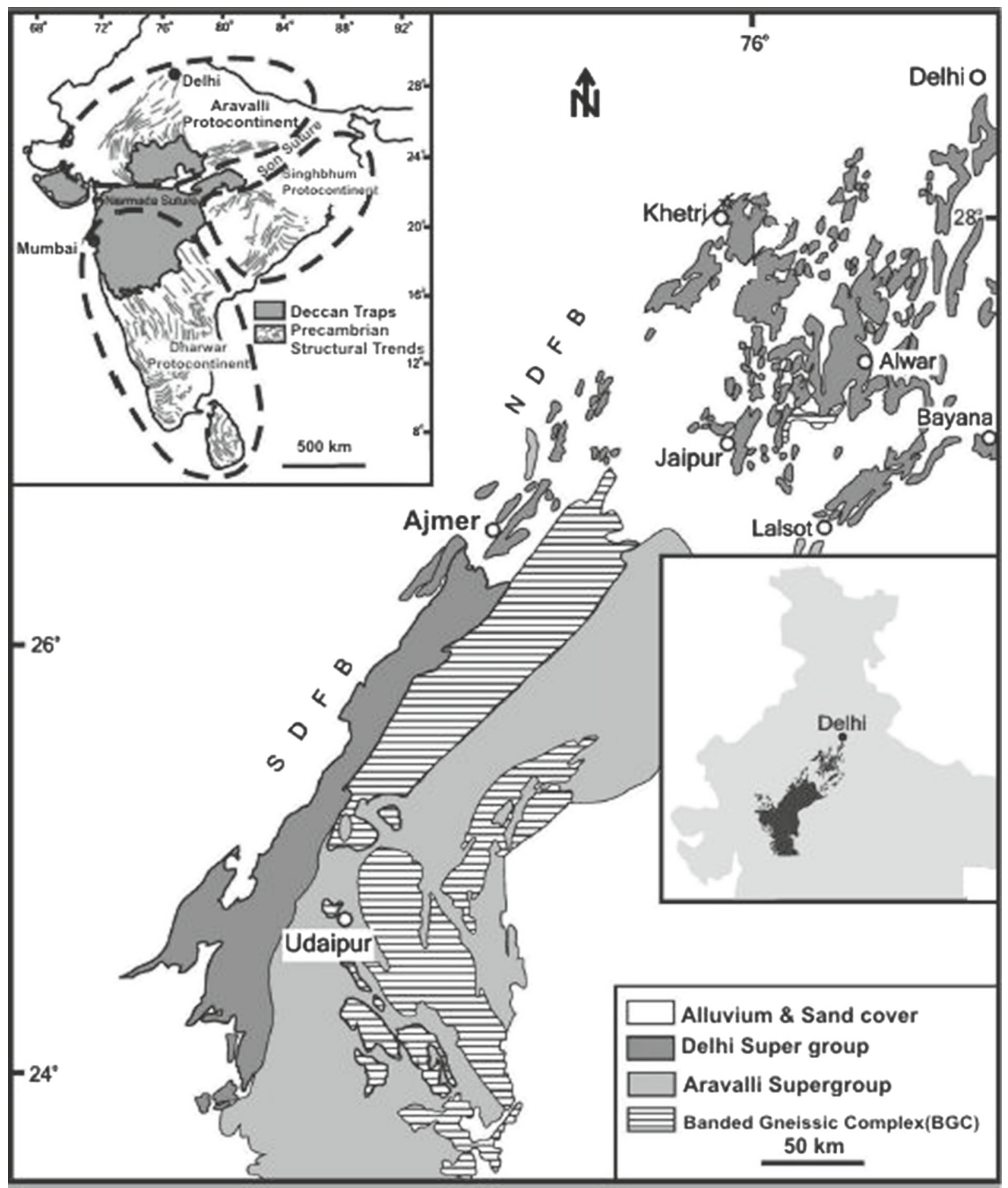

(b)

Figure 1. (Continued.)

it is quite deep and highly variable in the present geological setup.

\section{Review of VES data and interpretation}

VES investigation was performed in the month of July 2001 in order to know the quantitative knowledge of fresh water bearing aquifer and its thickness in the weathered/fractured quartzite rock formation. Secondly to locate the best possible borewell point for the rain water harvesting program within Hamdard University campus. The conventional VES was carried out at three different locations (figure 1a) in the campus with a maximum current electrode spacing (AB) varying from 300 to $500 \mathrm{~m}$ (IGGS Report 2001). The potential can be measured with a resolution of up to $0.1 \mathrm{mV}$. The 
raw VES field data is initially plotted on log-log graph paper with a modulus of $62.5 \mathrm{~mm}$ and manual interpretation being done with the help of standard master curves (Orellana and Mooney 1966; Rijkswaterstaat 1969). These interpreted results were further refined with the help of computer aided program and curve matching technique (Jupp and Vozoff 1975). The process of iteration goes on till the root mean square (RMS) error is minimized and finally display fairly the good match between the field and theoretical curves representing the final subsurface model parameters in terms of true resistivities and thicknesses $\left(\rho_{i}, h_{i}\right.$, $i=1,2, \ldots, n)$ for a given subsurface geological formation/layers. The model converges within 57 iterations indicating that the quality of data is good and it is also seen from the RMS error value for the individual model results. On analysis and interpretation of VES results it revealed six distinct geoelectric layers of the subsurface formations (figures 2-4). Qualitative interpretation indicates VES-1 is the combination of ' $\mathrm{H}$ ' type (Bowl type) and 'A' type of curve, VES-2 depicts 'H' type while VES-3 data shows 'A' type of curve. In terms of potentiality and groundwater availability, VES-1 site is more potential followed by VES-2 and VES-3 is the least potential site as seen from figures 2,3 and 4 , respectively. The geological strata comprising dry silty soil at the top followed by alternate layers of sand and clay as overburden and then fractured and fractured saturated quartzite rock at deeper levels. The interpreted VES results corroborated with the subsurface geological formation of the area. It is found that the resistivity values within $\sim 30-60 \Omega \mathrm{m}$ corresponds to fractured/jointed quartzite rock is considered as the potential aquifer. The geohydrological interpretation of the VES data suggests top soil/fine sand resistivity value $\sim 40-100 \Omega \mathrm{m}$, the clayey layer shows resistivity $<15 \Omega \mathrm{m}$, weathered quartzite 120-200 $\Omega \mathrm{m}$, saturated fractured/jointed quartzite gives $15-40 \Omega \mathrm{m}$ and massive quartzite showing $>800 \Omega \mathrm{m}$. From the inversion of resistivity data, the resistivity-depth models as presented in figures 2-4 and the nature of apparent resistivity curves, it is inferred that moderate to potential aquifer zone lies between 38 and $\sim 72 \mathrm{~m}$ depth at VES- 1 and 2 sites (figures 2 and 3 ) within the secondary porosity of host rock formation which is caused by joints and fractures while at VES-3 poor aquifer zone lies between 60 and $90 \mathrm{~m}$ depth as seen in figure 4.

\section{Materials and methods}

Electrical Resistivity Tomography (ERT) technique had been widely used in groundwater prospecting and exploration, engineering, environmental, hydrological problems and geothermal resource investigations. The resistivity field data first processed for eliminating any noisy or bad
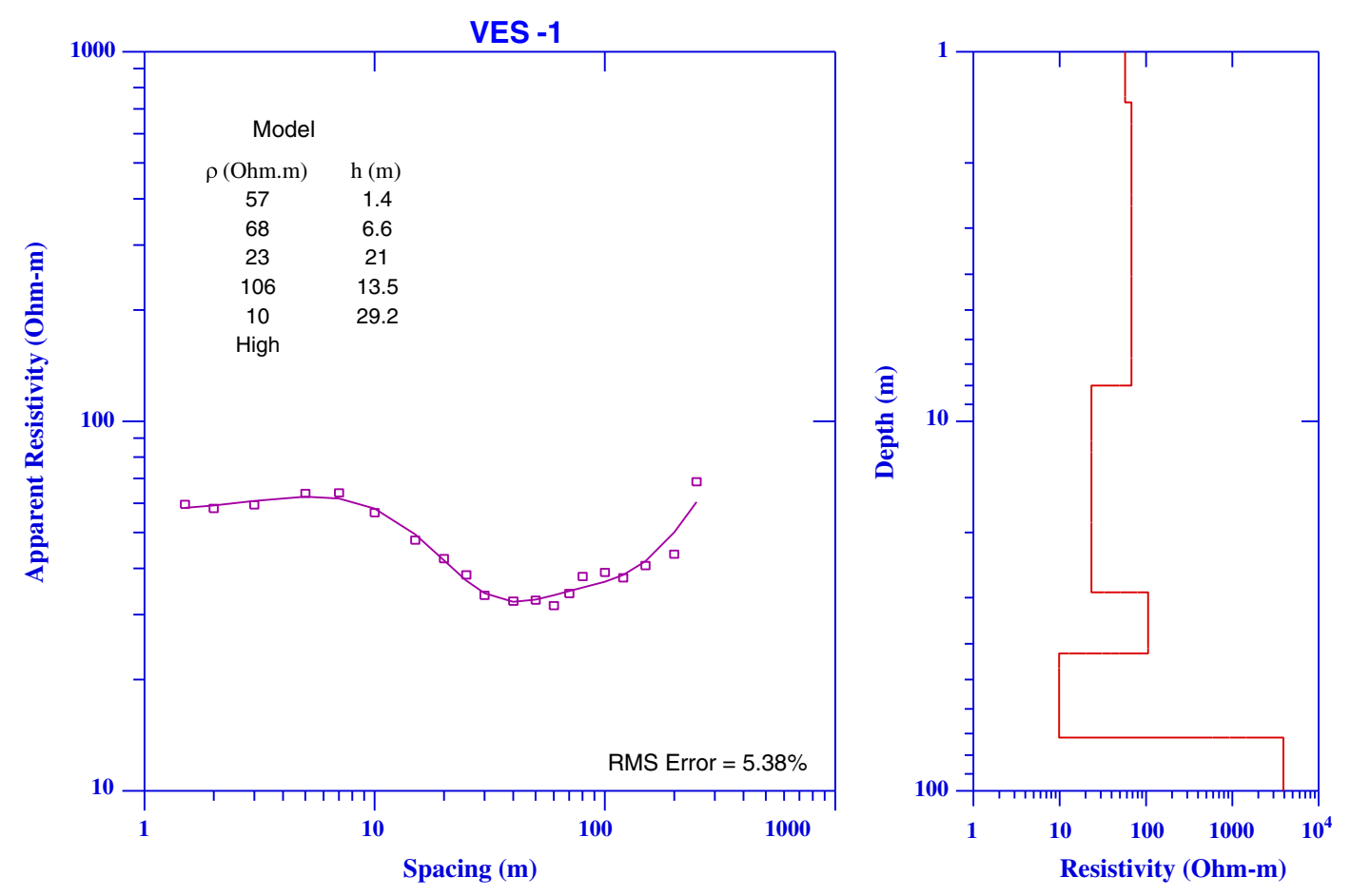

Figure 2. Showing the interpretation of VES-1 data (the square box is the field data and the smooth line is the computed curve) along with model layer parameters and resistivity vs. depth model. 

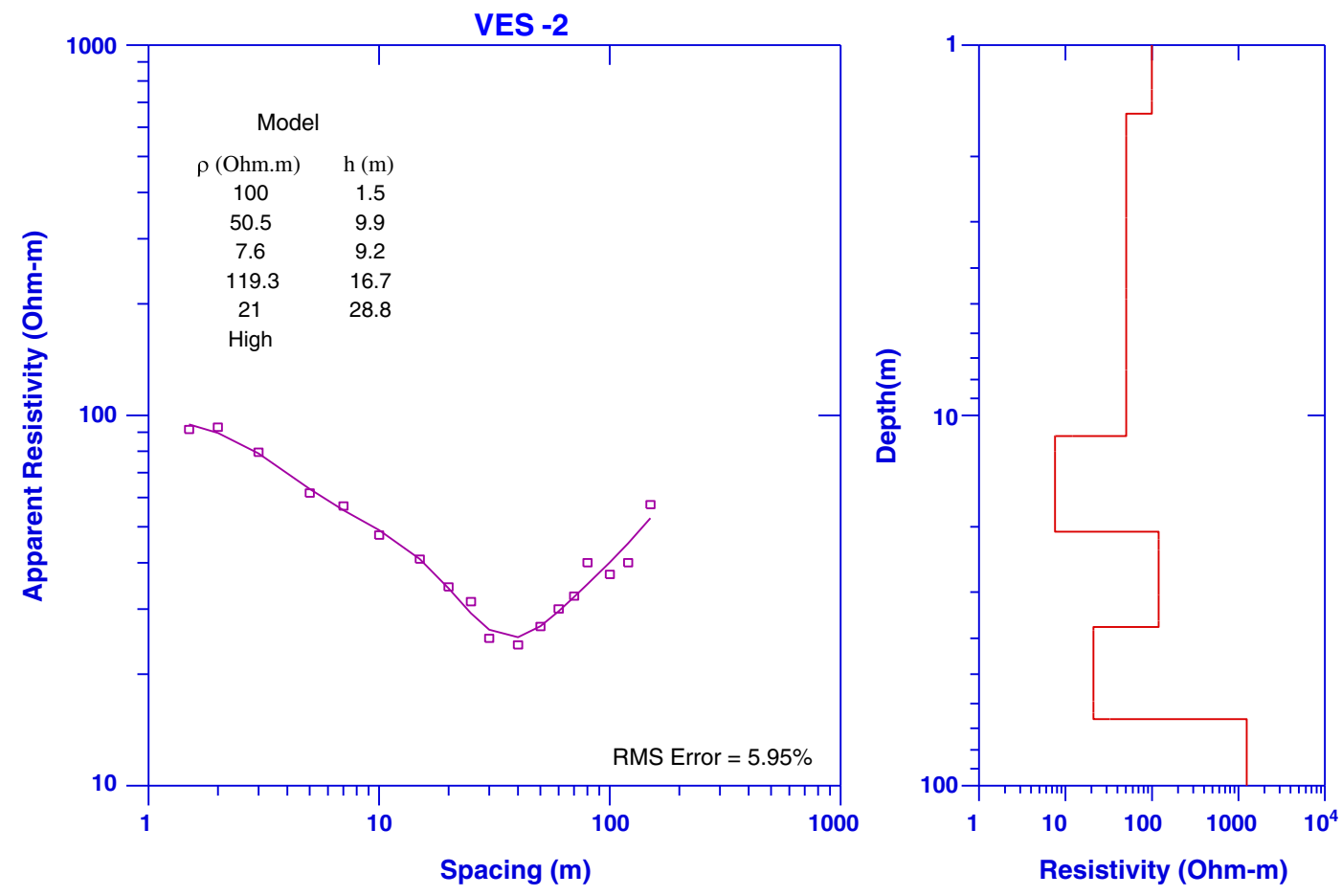

Figure 3. Showing the interpretation of VES-2 data (the square box is the field data and the smooth line is the computed curve) along with model layer parameters and resistivity vs. depth model.
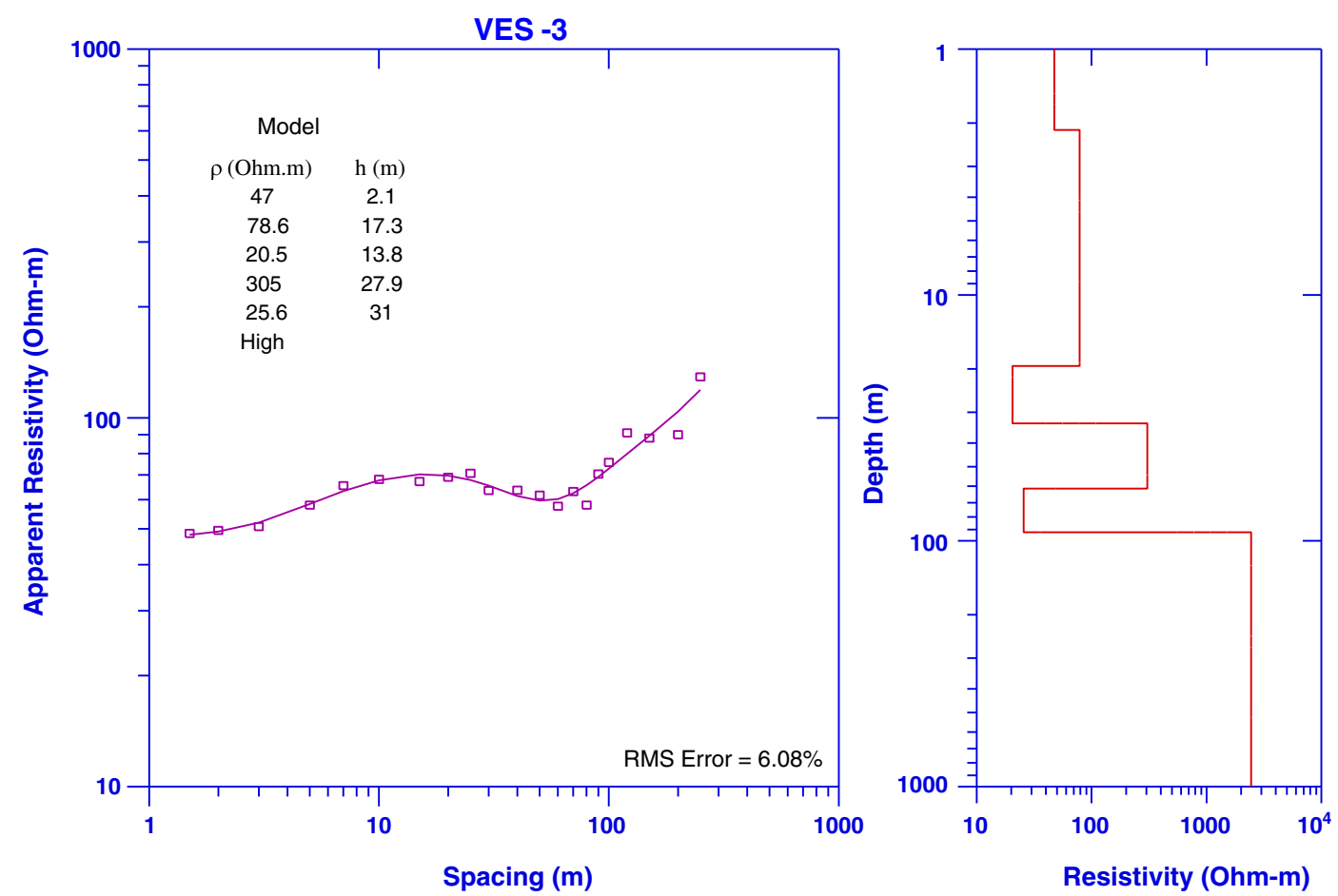

Figure 4. Showing the interpretation of VES-3 data (the square box is the field data and the smooth line is the computed curve) along with model layer parameters and resistivity vs. depth model.

data points in the gathered dataset and later depending on the smoothness of resistivity data, damping and mesh parameters had been assigned to the individual dataset in order to achieve realistic subsurface resistivity models. These field data are presented in the form of resistivity pseudo sections with dense sampling of apparent resistivity measurements at shallow depth (Loke 1997a, b) and are obtained in a short span of time with vast coverage both in lateral and 
vertical directions. The processed and filtered data is inverted using least squares inverse approach with smoothness constrained (Sasaki 1992; Loke 1997a, 1997b) and with a standard Gauss-Newton optimization technique by the help of Res2DINV software. This proved to be effective in eliminating electrode geometry effects so that the final inverted resistivity models provide an approximate image of the subsurface geology and hydrogeology. This actually reproduces an approximate subsurface resistivity variation with depth both in lateral and vertical directions. The inverted $2 \mathrm{D}$ resistivity section which is an approximation to the subsurface resistivity, in turn, finally interpreted in terms of geology and hydrogeology in the present hydrogeological context. However, it is a well known fact that the ground resistivity depends on various geological parameters such as the mineral content, intergranular compaction, porosity, degree of water saturation in the rocks, etc. (Marescot 1995).

First, a reconnaissance hydrogeological survey had been conducted in the area and later, adequate planning for feasibility to conduct multi-electrode resistivity tomography survey is performed for better groundwater prospecting. It is found that availability of longer length of linear space and hindrance of concrete roads, buildings and underlying wires limiting the electrical cable spread length (Rao et al. 2006). In view of this and keeping the objective of work in mind, pole-dipole and pole-pole arrays which are suitable for small electrode spacing and good horizontal coverage as well as deepest depths information had been selected for carrying the required study. At the same time the pole-dipole array had significantly higher signal strength to look closely the high resolution $2 \mathrm{D}$ resistivity data and also it is less affected by the remote electrode. While on the other hand, the pole-pole array had the widest horizontal coverage and deepest depth of investigation (Loke 1997a; Kumar 2004). The ERT investigation was conducted at four sites namely at gymnasium playground, near main building, near Majeedia Hospital and between 5th and 6th gate in Jamia Hamdard University campus, New Delhi (figure 1a). At site-1 and 2, the ERT is carried out using both pole-dipole and pole-pole configurations using 96 electrodes with $2 \mathrm{~m}$ electrode spacing while at site- 3 and 4 , it is possible to lay the electrical cable with $3 \mathrm{~m}$ spacing due to wider space availability. The length of the $2 \mathrm{D}$ resistivity profile ranges from 190 to $285 \mathrm{~m}$ during the entire field investigation. The data quality at sites 1 and 2 is bad especially for pole-pole array due to genuine problem in planting the infinity electrodes and in situ hindrance while at sites 3 and 4 data quality is good for both the arrays. The quality of the inversion result is related to the quality of the field resistivity data and is reflected in terms of RMS error on the inverted resistivity models, and is obtained by calculating the residuals between the measured and the calculated value of the apparent resistivity (Sudha et al. 2009).

\section{Results}

\subsection{Pole-dipole $2 D$ resistivity models}

The 2D inverted resistivity pole-dipole sections at site-1 (Gymnasium playground) and site-2 (near main building, figure 1a) show resistivity depth models of 25.3 and $27.2 \mathrm{~m}$, respectively (figures 5 and 6) while at site-3 (near Majeedia Hospital) and site-4 (between 5th and 6th gate, figure 1a) show resistivity depth models up to $41 \mathrm{~m}$ as shown in figures 7 and 8, respectively. At site-1 in SE end of the pole-dipole inverted resistivity section a low resistivity zone $<20 \Omega \mathrm{m}$ (figure 5 ) lateral layer is extending from centre to the SE end up to a depth of $\sim 20 \mathrm{~m}$ and is diminishing and shallower towards NW side and a similar anomaly is seen at the NW corner of the profile (figure 5). The zone in SE direction is inferred as the water bearing horizon at a shallow depth with limited water availability and is recharged from the near surface water body (figure 5 ). There is another water saturated zone of resistivity $\sim 20-30 \Omega \mathrm{m}$ equally visible at a depth of $25 \mathrm{~m}$ between lateral distance 32 and $64 \mathrm{~m}$ (figure 5). This clear opening in downward direction is likely the potential groundwater zone surrounded by comparatively higher resistivity $\sim 50-70 \Omega \mathrm{m}$ indicating weathered rock. Similarly, between lateral distance 80 and $110 \mathrm{~m}$ (figure 5) another low resistivity zone with a resistivity of $40-$ $60 \Omega \mathrm{m}$ at a similar $25 \mathrm{~m}$ depth is separated by a high resistivity body of the order $\sim 100 \Omega \mathrm{m}$ towards NW direction and bounded above by high resistivity rock $100-150 \Omega \mathrm{m}$ is yet another favourable site for groundwater exploration.

At site-2, the pole-dipole 2D inverted resistivity model depicts that the subsurface rock is highly heterogeneous and undulating in nature from west to east end of the profile (figure 6). It indicates water saturated zone with a resistivity in the range $\sim 10-20 \Omega \mathrm{m}$ at a depth of $\sim 15-27 \mathrm{~m}$ from west to east end of the profile (figure 6). Near the eastern end of the profile, due to very bad data acquisition at specific electrode positions had removed from the raw data and is seen as data gap in the $2 \mathrm{D}$ resistivity model (figure 6 ). Near the shallow part of the resistivity model it shows comparatively high resistivity in the range $\sim 40-100 \Omega \mathrm{m}$ showing rind development which is a common phenomenon in the area with outer layer less resistive and inner comparatively hard. Only in the deeper part, up 


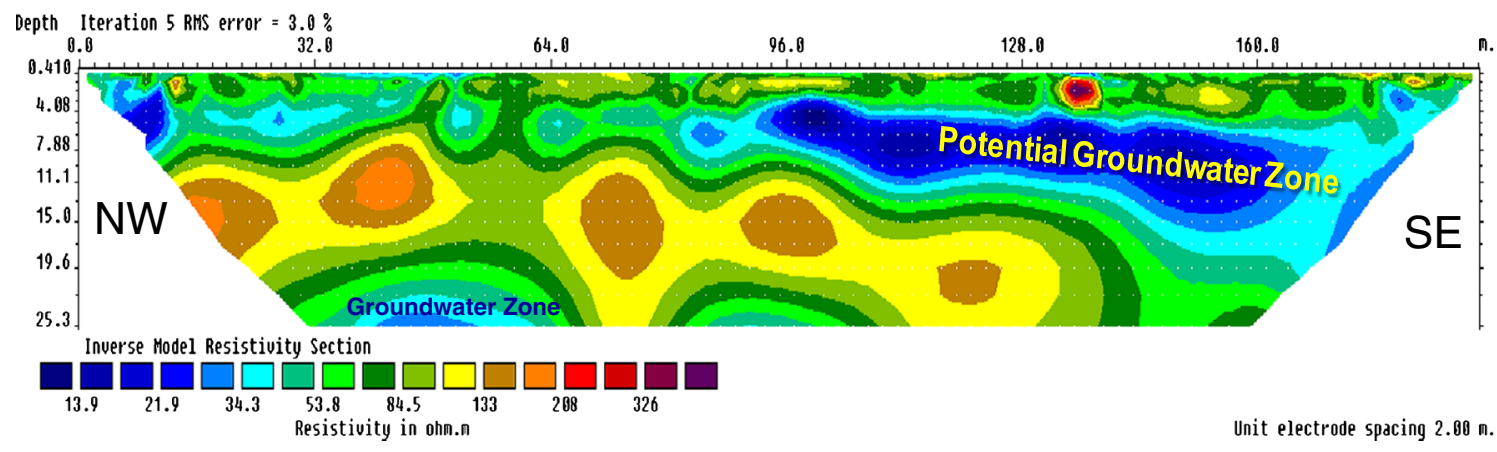

Figure 5. Showing pole-dipole 2D inverted resistivity section at Gymnasium playground at site-1 with clear cut groundwater zone reflecting substantial resistivity contrast as compared to host rock.

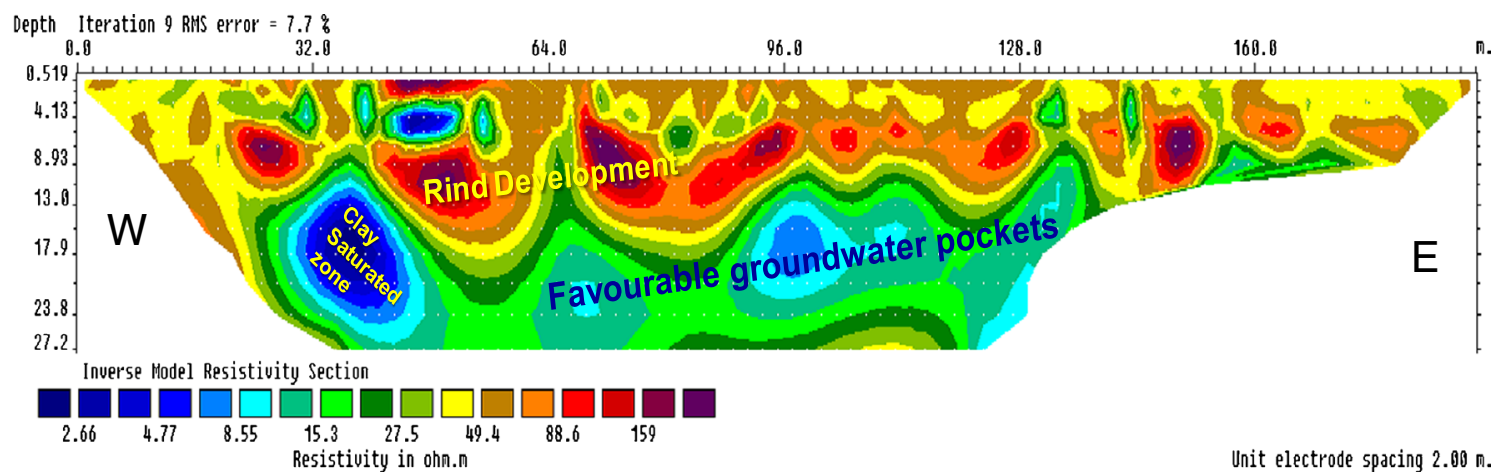

Figure 6. Showing pole-dipole 2D inverted resistivity section near main building at site-2 with highly heterogeneous subsurface rock with rind development and favourable groundwater pockets.
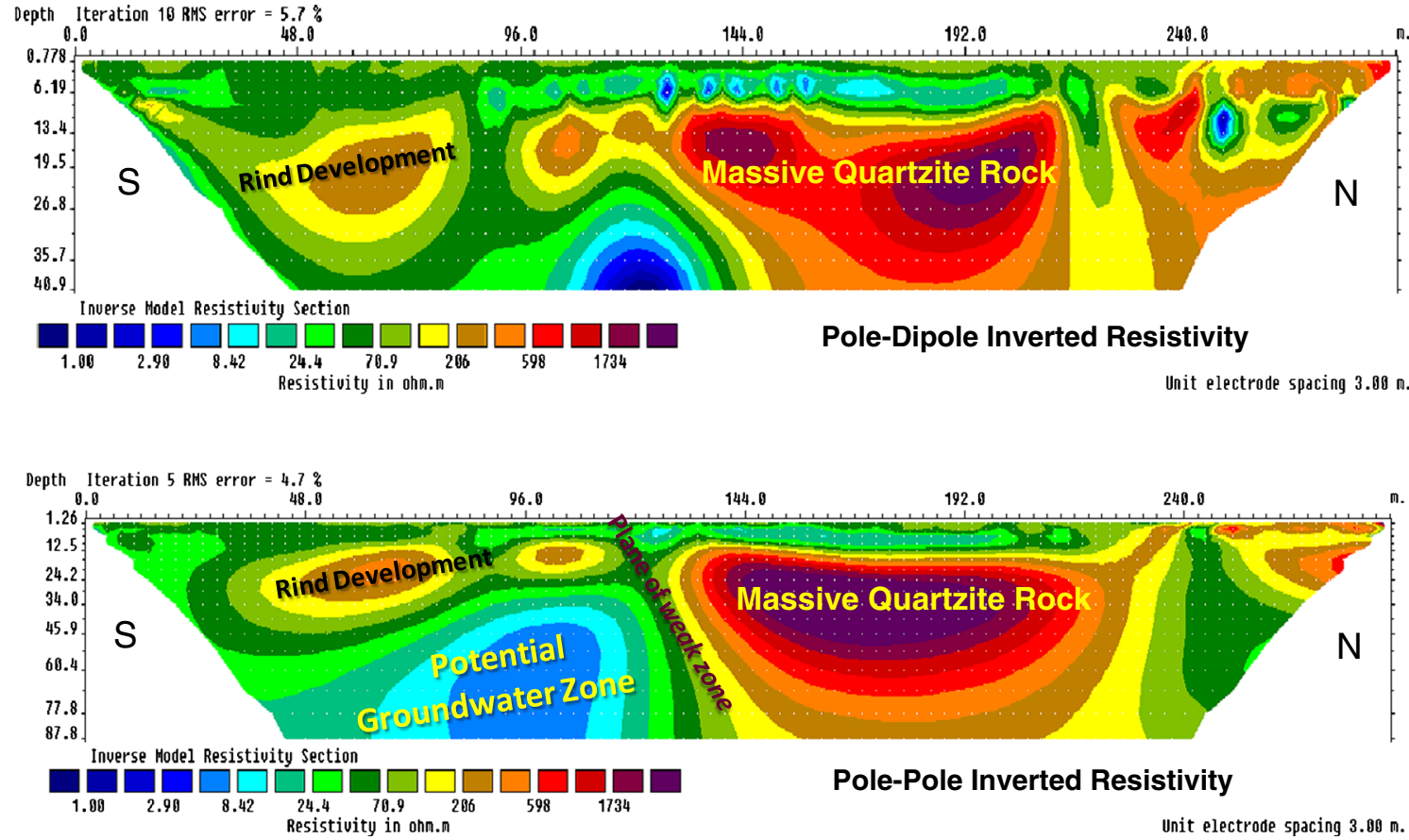

Figure 7. Showing pole-dipole and pole-pole 2D inverted resistivity sections near Majeedia Hospital at site-3 confirming the deeper resource of potential groundwater zone reflecting fairly large resistivity contrast between resistive and conductive formations (after Kumar 2012). 

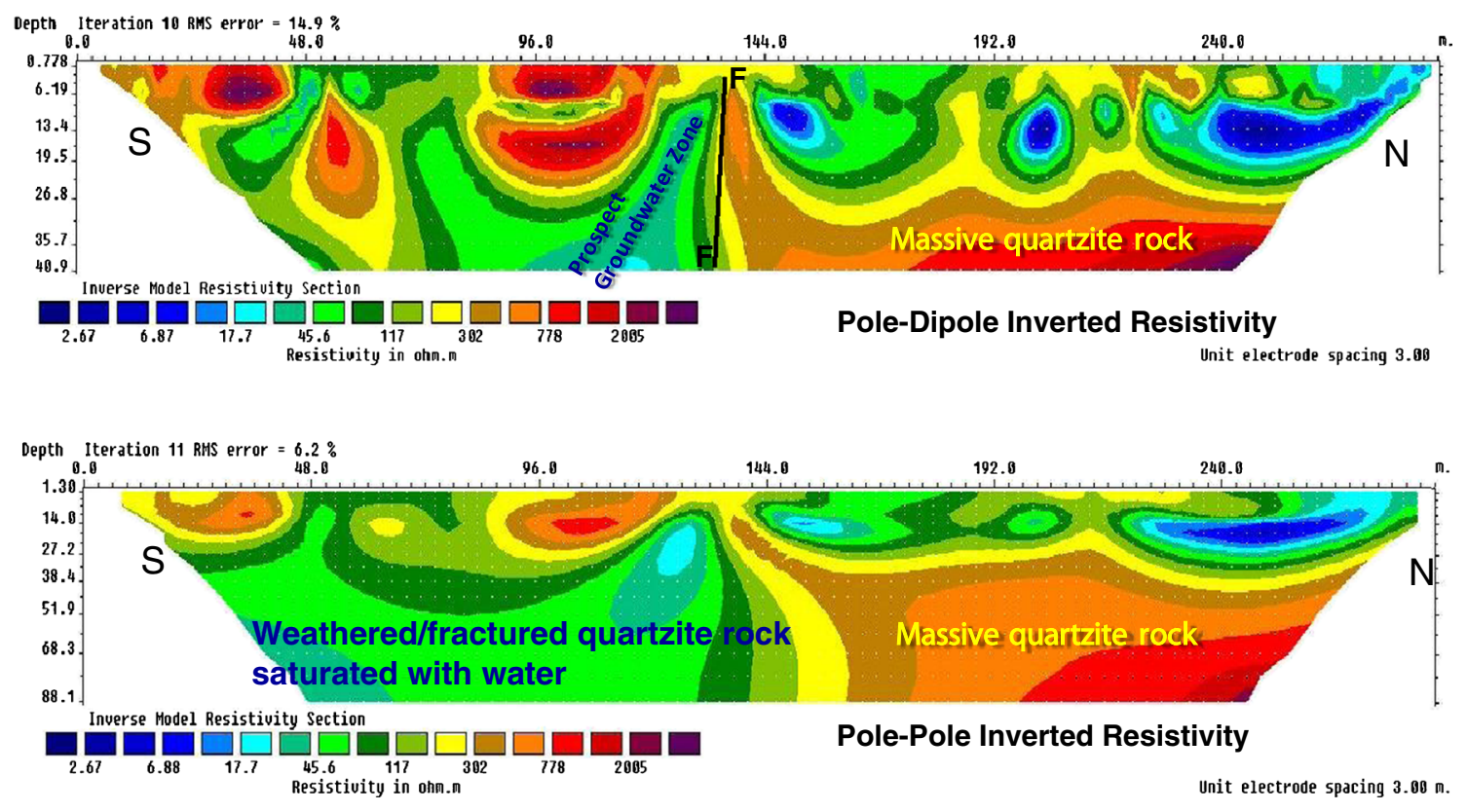

Figure 8. Showing pole-dipole and pole-pole 2D inverted resistivity sections between 5 th and 6 th gate at site- 4 with clear cut fault structure between resistive block and conductive zone along with prospect groundwater zone on the left side of the sections.

to a depth of $27 \mathrm{~m}$ the favourable groundwater pockets are seen (figure 6 ) and are bounded above by high resistivity 100-285 $\Omega \mathrm{m}$ tectonic disturbed rocks.

At site-3, the interpreted result of the 2D inverted pole-dipole resistivity section shows the phenomenon of clear cut rind development (figure 7) and the massive quartzite rock (Kumar 2012).

At site-4, 2D inverted pole-dipole resistivity section reflects quite heterogeneous with large resistivity variation of the subsurface formation (figure 8). The top layer is highly heterogeneous and the resistivity varies from $\sim 100$ to $5000 \Omega \mathrm{m}$ except near the north end where it is $<20 \Omega \mathrm{m}$. It is followed by high and low resistivity zones from south to north end of the profile. In the northern end, a low resistivity $<20 \Omega \mathrm{m}$ as seen in figure 8 at a depth between 10 and $15 \mathrm{~m}$ appears to be connected to the recharge source near the surface. This low resistivity zone is confined to a small region and is the effect of constant recharge from the surface. It is bounded above by weathered and semi-weathered quartzite rock and below by thick massive quartzite rock. At the centre of the profile a sharp contrasting structural feature originating from the bottom depth of $\sim 41 \mathrm{~m}$ till up to the surface is revealed and is separating high resistivity $\sim 300-700 \Omega \mathrm{m}$ and low resistivity $\sim 20-50 \Omega \mathrm{m}$ conducting zone (figure 8). The geological and tectonic feature seen in the model appear as if the massive block of rock is pushed up from NW to SE direction along the fault plane below $138 \mathrm{~m}$ distance (figure 8) and is clearly revealed up to $41 \mathrm{~m}$, the maximum depth of the profile.

\subsection{Pole-pole $2 D$ resistivity models}

The results obtained from the pole-pole 2D resistivity sections are not realistic at sites 1 and 2 due to poor quality of data at these two places because of real ground problem and hindrance in planting the far off infinity electrodes (i.e., $\infty$ electrodes). Only the result of pole-pole data for site- 4 is presented here. The result of the $2 \mathrm{D}$ inverted polepole resistivity section at site- 3 is recently published by Kumar (2012) describing the significance of the ERT technique in delineating the deeper groundwater resources. Only the inverted 2D resistivity model at site- 3 is depicted in figure 7 . One complete pseudosection for the measured apparent resistivity, the calculated apparent resistivity and the inverted resistivity model for pole-pole $2 \mathrm{D}$ resistivity data at site- 3 is shown in figure 9 for a comparison among themselves.

At site-4 (between 5th and 6th gate) ERT planned and carried out using $3 \mathrm{~m}$ electrode spacing along $\mathrm{S}-\mathrm{N}$ direction as presented in figure 8 . The 2D inverse resistivity model is shown in figure 8 . The pole-pole $2 \mathrm{D}$ data quality is very good at this site showing highly heterogeneous subsurface formation with clear and distinct anomalies of the order of $>1000 \Omega \mathrm{m}$ towards north side and low resistivity $<100 \Omega \mathrm{m}$ at southern end and centre of the profile, respectively. Based on the interpretation of the resistivity data into subsurface 


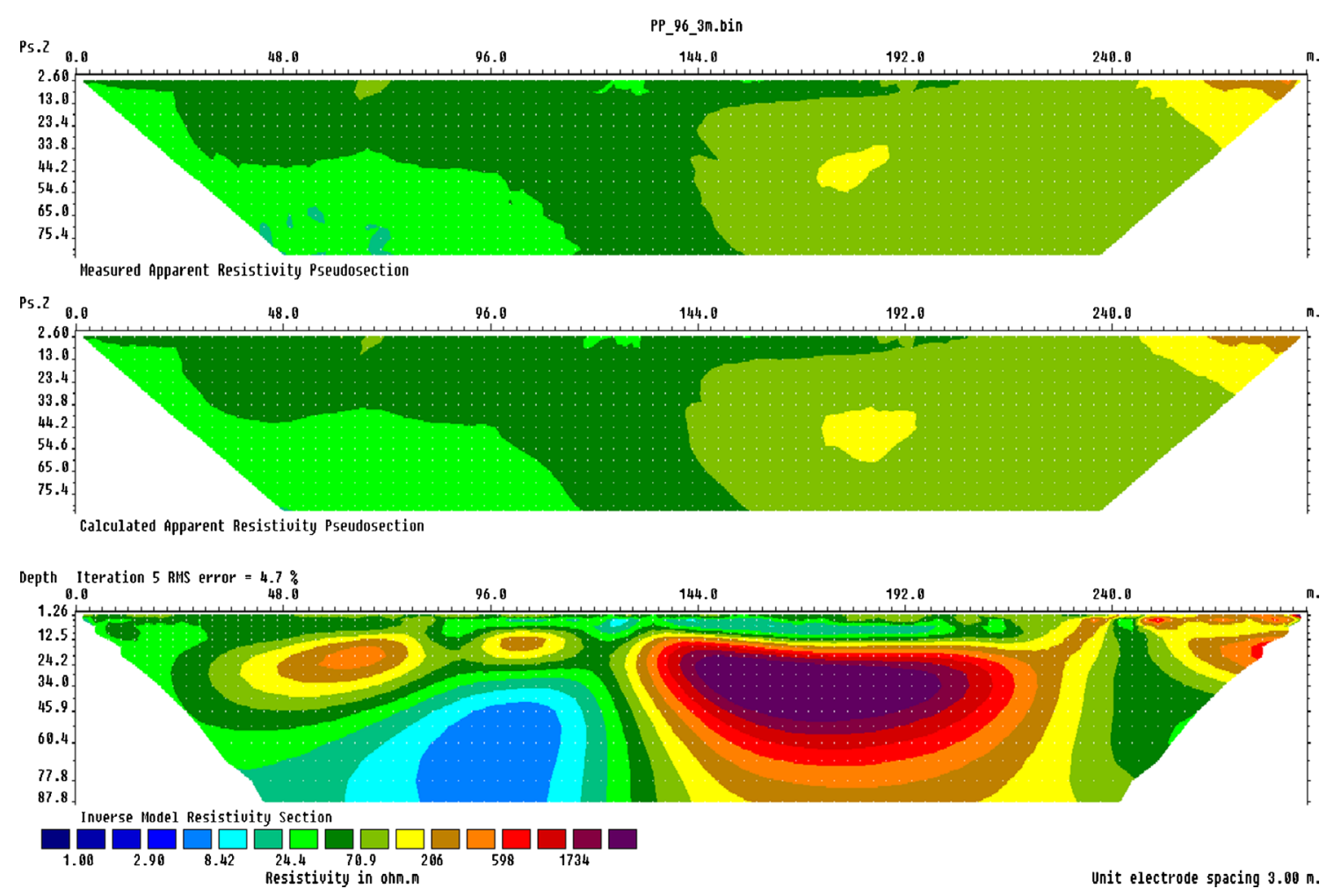

Figure 9. Shows the pseudo sections for measured apparent resistivity, calculated apparent resistivity and inverted resistivity model at site-3 for pole-pole array 2D resistivity data for a comparison among themselves.

geological and hydrogeological features, it is interpreted as quartzite massive rock and is continued to a depth from $\sim 35$ to $88 \mathrm{~m}$ in northern end of the profile (figure 8) which is better resolved with pole-pole data. The pole-pole inverse resistivity section (figure 8) divides the subsurface into two parts separating into one resistive and conductive block of rock and are clearly seen their extension up to a depth of $88 \mathrm{~m}$. The first part is up to $128 \mathrm{~m}$ on $2 \mathrm{D}$ line with high resistivity $>1000 \Omega \mathrm{m}$ to $\sim 5000 \Omega \mathrm{m}$ indicating the presence of highly massive quartzite rock towards northern end while the second part comprises low resistivity close to 20 $100 \Omega \mathrm{m}$ in southern end indicating the presence of clay and sand along with weathered/fractured quartzite rock saturated with water. From centre towards south at a depth of $35-88 \mathrm{~m}$ the complete zone is favourable for groundwater and is suitable for exploiting the deeper groundwater resource.

\section{Discussion of results}

The geological and hydrogeological setting of the area is relatively favourable for groundwater accumulation at deeper strata and augmentation with respect to previous $1 \mathrm{D}$ and present $2 \mathrm{D}$ resistivity investigations and their results. The results of the
VES data suggest top soil and sand resistivity lies between $\sim 40$ and $100 \Omega \mathrm{m}$, clayey layer shows resistivity $<15 \Omega \mathrm{m}$, weathered quartzite $120-200 \Omega \mathrm{m}$, saturated fractured/jointed quartzite shows $15-$ $40 \Omega \mathrm{m}$ while the massive quartzite shows $>800 \Omega \mathrm{m}$ with overlap of resistivity values for different litho units especially near the boundary. These results are also compared with the inverted $2 \mathrm{D}$ resistivity results. The hydrological condition is varying abruptly and depth to the static water levels of the aquifer ranges from 49.05 to $65.60 \mathrm{~m} \mathrm{bgl}$ which coincides with the hydrogeological interpretation of the inverted resistivity models. The litholog from the existing borewells reveals that the subsurface geological formations consist of clay, kankar, sand, weathered, fractured, highly fractured and massive quartzite rocks. These litho units were correlated with the inverted $2 \mathrm{D}$ resistivity models. The characteristic resistivities of the litho units are presented and discussed in table 1 . These interpreted geological formations are clay, clayey sand, weathered quartzite, semi-weathered, fractured quartzite and massive quartzite rock. The inferred resistivity from the inverted $2 \mathrm{D}$ resistivity models for clay lies in the range $<15 \Omega \mathrm{m}$, clayey sand and sand possess resistivity between $\sim 3$ and $35 \Omega \mathrm{m}$, weathered quartzite, semi-weathered and highly fractured quartzite saturated with water shows $<100 \Omega \mathrm{m}$, saturated fractured quartzite indicates 
Table 1. Showing the characteristics resistivity, the corresponding geological formation and the groundwater prospect evaluation.

\begin{tabular}{llll}
\hline & Characteristics resistivity inferred from & & \\
Sl. no. & 2D model resistivity data $(\Omega \mathrm{m})$ & Geological formation & Groundwater prospect \\
\hline 1 & $<15$ & Clay & Poor \\
2 & $\sim 3-35$ & Clayey sand and sand & Moderate to good \\
3 & $<100$ & Weathered, semi-weathered, & Very good with high potential \\
& & highly fractured quartzite & Good \\
4 & $100-150$ & saturated with water & Moderate \\
5 & $150-200$ & Saturated fractured quartzite & Less to moderate \\
7 & $200-1000$ & Fractured quartzite & Poor \\
\hline
\end{tabular}

100-150 $\Omega \mathrm{m}$, fractured quartzite falls between 150 and $200 \Omega \mathrm{m}$, sparsely fractured quartzite resistivity inferred as 200-1000 $\Omega \mathrm{m}$ while massive quartzite resistivity range $>1000 \Omega \mathrm{m}$ (table 1 ). In the present study, it is found and inferred that the clayeysand, sand, weathered quartzite, semi-weathered quartzite, fractured and highly fractured quartzite constitute the main aquifer. It had been possible to delineate and resolve the deeper groundwater prospect zones using specific pole-dipole and pole-pole $2 \mathrm{D}$ resistivity data and their inverted model results which are unclear in $1 \mathrm{D}$ results. The inverted 2D resistivity models depict both lateral and vertical continuous resistivity changes from surface to the depth of investigation and revealed the subsurface is highly heterogeneous with large variations in resistivity of geological formations and structure within the quartzite host rock region. Secondly, the large coverage of the area with more number of resistivity data points makes the resolution of the hydrogeological features much easier and closer in terms of interpretation as compared to the conventional resistivity study. The resistivity models show sharp resistivity contrast between the host rock and the water holding strata especially near the contact of two different geological formations. Nevertheless, the potential groundwater zones are reflected and are trapped in favourable environments like joints, lithological contacts weathered and fractured part of the rock.

The anomalous potential groundwater zones are seen at shallow depth in high resolution pole-dipole 2D data are very likely continuing and confirming the same anomalies in the deeper levels of $2 \mathrm{D}$ pole-pole resistivity sections. Interestingly, the distinct and clear large groundwater reserve delineated based on the high density resistivity tomography results where the aquifer resistivity ranges from $\sim 3$ to $35 \Omega \mathrm{m}$. Hydrogeologically this range of resistivity represents clayey sand and sand formation saturated with water while $<100-200 \Omega \mathrm{m}$ suggested highly fractured quartzite rock saturated with water. The range between 200 and $1000 \Omega \mathrm{m}$ indicates weathered/fractured quartzite rock and $>1000-5000 \Omega \mathrm{m}$ suggests completely massive basement rock as depicted in table 1 . Nevertheless, the presence of sharp resistivity contrast between high and low resistive geological features confirm the evidence of highly weathered/fractured quartzite, joints, shear/fault zones. The results delineated the lithological contact zones which are the principal target for potential groundwater resources in weathered and fractured saturated rock in the present geological medium.

\section{Conclusions}

ERT, an active source resistivity technique measurement, carried out in quartzitic hard rock formation in a highly tectonically disturbed ridge region, indicated clear and distinct resistivity anomalies in terms of groundwater potential zones for exploration. However, the results from 2D inverted resistivity models delineated and resolved the total depth of the aquifer which lies within the maximum depth of $88 \mathrm{~m}$. The reliability of the modelled resistivity of the subsurface formations is also validated by the litholog of the existing borehole data. The $2 \mathrm{D}$ resistivity models of the subsurface represent different lithologies, lithological contact zones, fault, structural features and thickness of the weathered regolith. Based on the hydrogeological interpretation of the $2 \mathrm{D}$ resistivity data there is all possibility for extension of the same aquifer in the present geological setting to still more depth of $\sim 200 \mathrm{~m}$ which can be exploited for groundwater resources in future for long term sustainability. The advantage of using pole-pole in conjunction with the pole-dipole array proved their capability which gives clear insight of the aquifer variability and their dimension from shallow to deeper levels from hydrogeological perspective in the present geological setting. 


\section{Acknowledgements}

Authors are thankful to the Director, CSIR National Geophysical Research Institute, Hyderabad India for his kind permission to carry out the work for societal and research benefit and encouragement to publish the important findings and results of this work. Thanks are also due to Mr. Azhar Ali Khan of JHU, New Delhi for extending logistic support and help during the geophysical and hydrological field survey. Authors thank Dr S Thiagarajan for helping in preparing the location map. Authors are extremely benefitted by the critical review of the manuscript by Ander Guinea and the anonymous reviewers for their constructive comments and suggestions which improved the quality of the research paper.

\section{References}

Abdulaziz A M, Hurtado J M and Faid A 2012 Hydrogeological characterization of Gold Valley: An investigation of precipitation recharge in an intermountain basin in the Death Valley region, California, USA; Hydrogeol. J. 20(4) 701-718.

Adepelumi A A, Yi M J, Kim J H, Ako B D and Son J S 2006 Integration of surface geophysical methods for fracture detection in crystalline bedrocks of southwestern Nigeria; Hydrogeol. J. 14 1284-1306.

Batayneh Awni T 2001 Resistivity imaging for near-surface resistive dyke using two-dimensional DC resistivity techniques; J. Appl. Geophys. 48 25-32.

Bhattacharya P K and Patra H P 1968 Direct current geoelectric sounding: Principles and interpretation; Methods in Geochem. Geophys., Series-9. Elsevier Publishing Company, 135p.

Daily W, Ramirez A, Binley A and Labrecque D 2004 Electrical Resistance Tomography; The Leading Edge 23(5) 438-442.

Giao P H, Chung S G, Kim D Y and Tanaka H 2003 Electric imaging and laboratory resistivity testing for geotechnical investigation of Pusan clay deposits; J. Appl. Geophys. 52 157-175.

Griffiths D H and Barker R D 1993 Two-dimensional resistivity imaging and modeling in areas of complex geology; J. Appl. Geophys. 29 211-226.

IGGS Report on Resistivity Survey for sitting a borewell location for rain water harvesting in Hamdard University Campus, New Delhi submitted by IGIS Sarita Vihar, New Delhi, 2001, 17p.

Jupp D L B and Vozoff K 1975 Stable iterative methods for the inversion of geophysical data; Geophys. J. Roy. Astron. Soc. 42 957-976.

Kaur P, Chaudhri N, Raczek I, Kröner A and Hofmann A W 2009 Record of $1.82 \mathrm{Ga}$ Andean-type continental arc magmatism in NE Rajasthan, India: Insights from zircon and $\mathrm{Sm}-\mathrm{Nd}$ ages, combined with $\mathrm{Nd}-\mathrm{Sr}$ isotope geochemistry; Gondwana Res. 16 56-71.

Keller G V and Frischknecht F C 1966 Electrical methods in geophysical prospecting; Pergamon Press Inc., Oxford.

Krishnamurthy N S, Kumar D, Negi B C, Jain S C, Dhar R L and Ahmed S 2000 Electrical resistivity investigation in Maheshwaram watershed, A.P., India; Technical Report No. NGRI-2000-GW-287.
Kumar D 2004 Conceptualization and optimal data requirement in simulating flow in weathered-fractured aquifers for groundwater management; Ph.D. Thesis, Osmania University, Hyderabad, 213p.

Kumar D 2012 Efficacy of electrical resistivity tomography technique in mapping shallow subsurface anomaly; J. Geol. Soc. India 80(3) 304-307.

Kumar D, Ahmed S, Krishnamurthy N S and Dewandel B 2007 Reducing ambiguities in vertical electrical sounding interpretations: A geostatistical application; J. Appl. Geophys. 62(1) 16-32.

Kumar D, Aadil N, Chandra S, Sreedevi P D, Khan Haris H, Dutta S, Zaidi F K, Sayed A, Krishnamurthy N S and Ahmed S 2008 Groundwater exploration in Basaltic formations at Ghatiya Watershed, Madhya Pradesh: An integrated study; Technical Report No. NGRI-2008GW-632.

Kumar D, Rao V A, Nagaiah E, Raju P K, Mallesh D, Ahmeduddin M and Ahmed S 2010 Integrated geophysical study to decipher potential groundwater and Zeolite-bearing zones in Deccan Traps; Curr. Sci. 98(6) 803-814.

Kumar D, Rai S N, Thiagarajan S, Ratna Kumari Y and Bulliabai M 2011 Sensitivity analysis of 2d electrical resistivity data for groundwater exploration in deccan basalt hard rock aquifers; Presented and published in Abstract volume on Andhra Pradesh Science Congress2011 on focal theme Science for the Society held at Visakhapatnam during 14-16 November 2011, 194p.

Loke M H 1997a Electrical imaging surveys for environmental and engineering studies: A practical guide to 2-D and 3-D surveys; 61p.

Loke M H 1997b Software: RES2DINV. 2D interpretation for DC resistivity and IP for windows 95. Copyright by MH Loke 5, Cangkat Minden Lorong 6, Minden Heights, 11700 Penang, Malaysia.

Marescot L 1995 Electrical surveying. Part-I: Resistivity method; Lecture A. WS0506.

Orellana E and Mooney H M 1966 Master Tables and Curves for Vertical Electrical Sounding Over Layered Structures; Interciencia, Madrid, Spain.

Owen R J, Gwavava O and Gwaze P 2005 Multi-electrode resistivity survey for groundwater exploration in the Harare greenstone belt, Zimbabwe; Hydrogeol. J. 14 244-252.

Parasnis D S 1986 Principles of applied geophysics; 4th edn, Chapman and Hall, London, UK, 402p.

Rao V A, Kumar D, Sarma V S, Khan A A and Ahmed S 2006 Multi-Electrode Resistivity Imaging Survey for groundwater exploration in Jamia Hamdard University Campus, New Delhi, Technical Report No. NGRI-2006GW-578.

Rao V A, Kumar D, Chandra S, Nagaiah E, Kumar G A, Syed A and Ahmed S 2008 High-Resolution Electrical Resistivity Tomography (HERT) Survey for groundwater exploration at APSP Campus, Dichpally, Nizamabad District, Andhra Pradesh, Technical Report No. NGRI-2008-GW-626.

Ratnakumari Y, Rai S N, Thiagarajan S and Kumar D 2012 2D Electrical resistivity imaging for delineation of deeper aquifers in parts of Chandrabhaga river basin, Nagpur district, Maharashtra, India; Curr. Sci. 102(1) 61-69.

Revil A, Karaoulis M, Johnson T and Kemna A 2012 Review: Some low-frequency electrical methods for subsurface characterization and monitoring in hydrogeology; Hydrogeol. J. 20(4) 617-658.

Rijkswaterstaat 1969 Standard Graphs for Resistivity Prospecting; European Association of Exploration Geophysicists, Hague, The Netherlands. 
Robert $\mathrm{T}$, Dassargues $\mathrm{A}$, Brouyère $\mathrm{S}$, Kaufmann $\mathrm{O}$, Hallet V and Nguyen F 2011 Assessing the contribution of electrical resistivity tomography (ERT) and self-potential (SP) methods for a water well drilling program in fractured/karstified limestones; J. Appl. Geophys. 75 42-53.

Sasaki Y 1992 Resolution of resistivity tomography inferred from numerical simulation; Geophys. Prospect. 40 453-464.
Sudha K, Israil M, Mittal S and Rai J 2009 Soil characterization using electrical resistivity tomography and geotechnical investigations; J. Appl. Geophys. 67 74-79.

Zohdy A A R, Eaton G P and Mabey D R 1974 Application of surface geophysics to groundwater investigation, Techniques of Water Resources Investigations, US Geol. Surv., 116p.

MS received 10 October 2012; revised 25 June 2013; accepted 9 September 2013 